\title{
OCORRÊNCIA DE CEPAS DE ESTAFILOCOCOS COAGULASE POSITIVA FORMADORAS DE COLÔNIAS ATÍPICAS EM ÁGAR BAIRD- PARKER EM QUEIJOS MATURADOS
}

\author{
CLEUBE A. BOARI * \\ ROBERTA H. PICCOLI-VALLE * \\ ADENILDE R. NASCIMENTO ** \\ ELIANE M.C. ALCÂNTARA *
}

\begin{abstract}
Avaliou-se a presença de cepas de estafilococos coagulase positiva formadoras de colônias atípicas em 16 queijos maturados de vários tipos comercializados na cidade de Lavras, MG (Brasil). Diluições apropriadas foram semeadas em ágar Baird-Parker e as colônias isoladas foram submetidas à coloração de Gram e às provas de catalase, de oxidase, de coagulase, de termonuclease, de crescimento em aerobiose, em anaerobiose e em presença de $\mathrm{NaCl} 15 \%$. Das 43 colônias atípicas avaliadas, 28 (65,1\%) foram confirmadas como estafilococos produtores de coagulase e $10(23,3 \%)$ identificadas como S. aureus. Colônias atípicas em ágar Baird-Parker obtidas de queijos maturados devem ser submetidas a testes para identificação, pois podem corresponder a cepas produtoras de toxinas.
\end{abstract}

PALAVRAS-CHAVE: QUEIJOS; ESTAFILOCOCOS COAGULASE POSITIVA; Staphylococcus aureus; ÁGAR BAIRD-PARKER.

\section{INTRODUÇÃO}

Staphylococcus aureus é responsável por um dos tipos mais freqüentes de intoxicação alimentar, comumente veiculada por leite e derivados (SANTOS, GENIGEORGIS e FARVER, 1991). Durante seu crescimento nesses produtos, cepas enterotoxigênicas da bactéria produzem toxinas termo-estáveis que causam náuseas, vômitos e diarréia quando ingeridas em quantidade suficiente (HALPIN-DOHNALEK e MARTH, 1989). Embora

* Departamento de Ciência dos Alimentos, Universidade Federal de Lavras, Lavras, MG - Brazil. (e-mail: rvalle@ufla.br).

** Departamento de Tecnologia Química, Universidade Federal do Maranhão, Bacanga, São Luis, MA, Brazil. 
possa estar presente no leite, especialmente nos provenientes de vacas mastíticas, a detecção de $S$. aureus em queijos elaborados com leite pasteurizado é fruto de contaminação posterior dos mesmos, pois o tratamento térmico é eficiente na eliminação de células viáveis dessa bactéria (HALPIN-DOHNALEK e MARTH, 1989).

A resolução RDC no 12 (de 2 de janeiro de 2001), do Ministério da Saúde estabelece o limite de $10^{3} \mathrm{UFC} / \mathrm{g}$ para cepas de estafilococos produtoras de coagulase em queijos frescos ou maturados coletados no comércio (BRASIL, 2001). O método usualmente empregado para a quantificação de estafilococos coagulase positiva em alimentos é a contagem de colônias em placas com meio ágar Baird-Parker (ICMSF, 1982; AOAC, 1990). Nesse meio, a recuperação de células bacterianas injuriadas é favorecida pela presença de piruvato de sódio. O crescimento de outras bactérias, mas não o de estafilococos coagulase positiva, é inibido pelos agentes seletivos glicina e cloreto de lítio. A redução do telurito de potássio presente no meio confere coloração brilhante negra-acinzentada às colônias. Colônias típicas apresentam de 1 a 1,5 mm de diâmetro. São circundadas por halo opaco, resultante da atividade lipolítica do microrganismo sobre a emulsão de gema de ovo do meio, e outro claro oriundo de sua ação proteolítica sobre a mesma (SILVA et al., 1997).

Surtos de intoxicação alimentar de origem estafilocócica são, principalmente, associados à cepas que produzem colônias típicas em meio com emulsão de gema de ovo. Usualmente, colônias atípicas desprovidas de halo não são repicadas e submetidas a testes para confirmação (HARRIGAN, 1998). Entretanto, tais colônias podem corresponder a cepas de estafilococos potencialmente produtoras de toxinas, comuns em leite cru (SILVA et al., 2000). Cepa de $S$. aureus com morfologia atípica em meio MSEY (manitol - sal - gema de ovo ágar) foi relatada como causadora de surto de infecção alimentar no Japão (MIWA et al., 2001). Deriva desses fatos a necessidade de se testar as colônias atípicas, visando a avaliação segura de contaminação por estafilococos coagulase positiva.

Avaliações realizadas em diferentes tipos de queijo, na região de Lavras (MG), evidenciaram números expressivos de colônias atípicas em ágar Baird-Parker para a maioria das amostras testadas. O objetivo deste trabalho foi verificar se tais colônias atípicas poderiam corresponder a cepas de estafilococos coagulase-positivas e, portanto, representar risco ao consumidor. 


\section{MATERIAL E MÉTODOS}

\subsection{AMOSTRAS}

Neste estudo foram analisadas 16 amostras de queijo, adquiridas no comércio da cidade de Lavras, Estado de Minas Gerais. Foram coletados 2 queijos tipo Gorgonzola, 2 tipo Brie, 2 tipo Saint-Paulin, 2 tipo Edam, 2 tipo Morbier, 1 tipo Provolone, 1 tipo Gruyère, 1 fundido tipo Gruyère, 1 tipo Cammembert, 1 tipo Gouda, e 1 tipo Itálico. As embalagens originais dos queijos foram abertas no laboratório apenas no momento de retirada das amostras.

\subsection{PREPARO DA AMOSTRA}

Amostras de $25 \mathrm{~g}$ de cada queijo foram homogeneizadas em solução de citrato de sódio $2 \%$ ( $p / v)$, em liqüidificador doméstico, sendo realizadas diluições seriadas em água peptonada $0,1 \%(p / v)$.

\subsection{ISOLAMENTO E CARACTERIZAÇÃO DE Staphylococcus aureus}

Alíquotas de $0,1 \mathrm{~mL}$ das diluições apropriadas foram semeadas em placas de Petri, contendo ágar Baird-Parker e incubadas a $37^{\circ} \mathrm{C}$ por 24 horas (HARRIGAN, 1998). Foram inoculadas concomitantemente, em duas placas controle, alíquotas de $0,1 \mathrm{~mL}$ da diluição apropriada de cultura de uma cepa de estafilococos formadora de colônias típicas, isolada no Laboratório de Microbiologia de Alimentos da Universidade Federal de Lavras. Após a incubação e contagem das colônias, três a cinco colônias de cada placa foram transferidas para tubos contendo ágar para contagem padrão, incubadas a $37^{\circ} \mathrm{C}$ por $24 \mathrm{~h}$ e estocadas sob refrigeração. As culturas estocadas foram cultivadas em caldo $\mathrm{BHI}$ a $37^{\circ} \mathrm{C}$ por $24 \mathrm{~h}$ e a seguir submetidas à coloração de Gram e às provas de catalase, de coagulase, de termonuclease, de crescimento em presença de $15 \%$ de $\mathrm{NaCl}$, de oxidase e de crescimento em anaerobiose e em aerobiose em caldo glicose-vermelho de fenol (MAC FADDIN, 1980).

\section{RESULTADOS E DISCUSSÃO}

Não foram encontradas colônias típicas de estafilococos coagulase positiva em nenhuma das amostras avaliadas, embora colônias típicas 
tenham sido observadas nas placas inoculadas com a cultura controle. Nas placas inoculadas com a amostra do queijo fundido tipo Gruyère e com uma das amostras dos queijos tipo Saint-Paulin, Morbier, Edam e Brie não houve crescimento bacteriano. Colônias com tamanho em torno de $1,5 \mathrm{~mm}$, coloração negra-acinzentada brilhante e sem halos foram encontradas nas placas provenientes das demais amostras. Três a cinco colônias de cada amostra foram selecionadas para a realização dos testes bioquímicos, totalizando 43 colônias. O Quadro 1 mostra os resultados obtidos nas provas de coagulase e termonuclease para as colônias testadas.

\section{QUADRO 1-RESULTADOS OBTIDOS NAS PROVAS DE COAGULASE E TERMONUCLEASE REALIZADAS EM 43 CEPAS DE ESTAFILOCOCOS ISOLADAS DE QUEIJOS MATURADOS}

\begin{tabular}{|lccccc|}
\hline & \multicolumn{3}{c}{ Coagulase } & \multicolumn{2}{c|}{ Termonuclease } \\
\cline { 2 - 6 } & 4+ ou 3+ & 2+ ou 1+ & negativo & positivo & negativo \\
\cline { 2 - 6 } Percentagem \\
de cepas (\%) & $9,3(4)$ & $79,1(34)$ & $11,6(5)$ & $30,23(13)$ & $69,77(30)$ \\
\hline
\end{tabular}

( ) - número correspondente de cepas.

Das colônias analisadas, 10 (23,3\%) foram identificadas como S. aureus, sendo considerados também os resultados de coagulase 1+e 2+ para a identificação. As demais cepas foram identificadas como $S$. delfini $(65,1 \%)$, S. schleiferi $(7,0 \%)$ e S. warneri $(4,6 \%)$, espécies de estafilococos não-produtoras de enterotoxinas.

Contaminação por $S$. aureus foi detectada em uma das amostras de

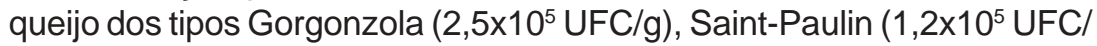

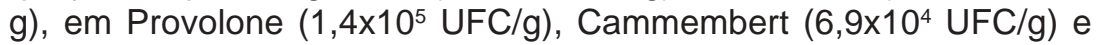
Gruyère $\left(2,7 \times 10^{5} \mathrm{UFC} / \mathrm{g}\right)$. Em outras sete amostras não foi detectada contaminação por $S$. aureus, sendo identificadas apenas as espécies de estafilococos não produtoras de toxinas mencionadas acima.

O isolamento de colônias sem halos ou atípicas de estafilococos coagulase positiva em ágar Baird-Parker é comum em leite proveniente de vacas com mastite (SILVA et al., 2000; ICMSF, 1982). Essas colônias 
muitas vezes são desprezadas no momento da análise microbiológica, não sendo submetidas aos testes bioquímicos. A ausência de colônias típicas não implica em segurança para o consumidor, uma vez que cepas de estafilococos coagulase positiva não-produtoras de lipases podem causar surtos de intoxicação (MIWA et al., 2001). A identificação de cepas de estafilococos coagulase positiva formadoras de colônias atípicas a partir de queijos maturados sugere que, colônias deste tipo também devem ser submetidas aos testes de identificação.

O ICMSF (1996) não recomenda que se considere cepas produtoras de coagulase fraca (1+ ou 2+) como positivas nas avaliações dos testes bioquímicos para identificação de $S$. aureus, uma vez que outras espécies de estafilococos podem produzir pequenas quantidades dessa enzima. Contudo, protocolos sugeridos pela AOAC (1990), por HARRIGAN (1998) e MAC FADDIN (1980) consideram-nas como positivas. SILVA et al. (2000) demostraram que cepas produtoras de coagulase fraca não consideradas provocaram avaliação subestimada do número de unidades formadoras de colônias (UFC) de $S$. aureus presentes em leite oriundo de vacas mastíticas.

A presença de $S$. aureus em alimentos é comum. Muitas vezes o alimento é contaminado pelo manipulador, pois cerca de $50 \%$ dos seres humanos são portadores deste microrganismo (ICMSF, 1996). Sua presença em queijos elaborados com leite pasteurizado é atribuída a esse tipo de contaminação, uma vez que a pasteurização é eficiente na sua eliminação. Entretanto, a detecção de estafilococos em queijos maturados não é comum, pois conforme as alterações químicas e microbiológicas ocorrem, esses microrganismos deixam de ser detectados no interior dos queijos, principalmente naqueles maturados por mais de 60 dias (ZÁRATE et al., 1997). De fato, cinco das 16 amostras analisadas mostraram-se livres de contaminação por estafilococos e seis apresentaram apenas espécies não-toxigênicas. Porém, uma amostra de queijo dos tipos Gorgonzola, Saint-Paulin, Provolone, Cammembert e Gruyère apresentaram contagens elevadas de $S$. aureus, superiores ao limite estabelecido pela legislação vigente $\left(1 \times 10^{3} \mathrm{UFC} / \mathrm{g}\right)$. A presença desse microrganismo pode ser devida à elevada concentração inicial no produto ou ao tempo reduzido de maturação. Em ambos os casos, a qualidade higiênico-sanitária dos produtos é preocupante, pois a concentração de cerca de $1 \times 10^{5} \mathrm{UFC} / \mathrm{g}$ de $S$. aureus no alimento pode ser suficiente para a produção de toxinas em níveis capazes de causar intoxicação alimentar (ICMSF, 1996). Como esse microrganismo foi detectado em queijos adquiridos no mercado, que já haviam cumprido período de maturação, números superiores de 
S. aureus deviam estar presentes no produto. Os queijos apresentam boas condições de multiplicação e produção de toxina por $S$. aureus. Sendo assim, esses produtos poderiam causar toxinose nos consumidores, uma vez que, a toxina estafilocócica apresenta grande estabilidade em diversas condições ambientais.

A presença de colônias atípicas pode levar o analista a desprezá-las no processo de confirmação de $S$. aureus ou estafilococos produtores de coagulase, fazendo com que o produto seja considerado apto para o consumo quando na realidade não está.

\title{
4 CONCLUSÃO
}

Queijos maturados em sua maioria não apresentam contagens significativas de estafilococos coagulase positiva, contudo quando analisados após pequeno período de maturação podem apresentar elevados índices desses microrganismo. Esses podem apresentar-se de forma atípica levando à sua desconsideração em análises laboratoriais, para confirmação de $S$. aureus ou estafilococos produtor de coagulase. Tal fato pode provocar caso ou surto de toxinose no consumidor, uma vez que esse microrganismo encontra boas condições no queijo para se multiplicar e/ou produzir toxina.

\begin{abstract}
OCURRENCE OF COAGULASE POSITIVE STAPHYLOCOCCUS STRAINS FORMING ATYPICAL COLONIES IN BAIRD-PARKER AGAR ON RIPENED CHEESE

The presence of coagulase positive staphylococcus strains forming atypical colonies were evaluated in 16 ripened cheeses of various sorts marketed in the city of Lavras. Adequate dilutions were plated on Baird-Parker agar and the isolate colonies were subjected to the Gram staining and tests of catalase, oxidase, coagulase, thermonuclease, growth in aerobiosis, in anaerobiosis and in the presence of $15 \%$ $\mathrm{NaCl}$. Out of the 43 atypical colonies evaluated, 28 (65.1\%) were confirmed as coagulase positive Staphylococcus strains and 10 (23.35\%) were identified as S. aureus. Atypical colonies in Baird-Parker agar originated from ripened cheeses must be subjected to tests for identification, since they may correspond to enterotoxin-producing strain. KEY-WORDS: COAGULASE POSITIVE STAPHYLOCOCCUS; Staphylococcus aureus; CHEESE; BAIRD-PARKER AGAR
\end{abstract}

\section{REFERÊNCIAS}

1 AOAC. Association of Official Analytical Chemists. Staphylococcus 
aureus in foods. In: HELRICH, K. (Ed.). Official methods of analysis of AOAC International. $15^{\text {th }} \mathrm{ed}$. Arlington, VA, 1990.

2 BRASIL. Ministério da Saúde. Secretaria de Vigilância Sanitária. Resolução RDC ㄲo 12, de 02 de janeiro de 2001. Regulamento técnico sobre padrões microbiológicos para alimentos. Diário Oficial [da] República Federativa do Brasil, Brasília, n. 7-E, 10 jan. 2001. p. 45-53.

3 HALPIN-DOHNALEK, M.I.; MARTH, E.H. Staphylococcus aureus: production of extracellular compounds and behavior in foods: a review. Journal of Food Protection, v. 52, p. 267-282,1989.

4 HARRIGAN, W.F. Laboratory methods in food microbiology. $3^{\text {rd }}$ ed. San Diego: Academic, 1998.

5 ICMSF. International Comission on Microbiological Specifications For Foods. Microrganismos de los alimentos 1. Técnicas de análisis microbiológico. 2. ed. Zaragoza: Acribia, 1982. 431 p.

6 ICMSF. International Comission on Microbiological Specifications for Foods. Microrganismos de los alimentos: características de los patógenos microbianos. Zaragoza: Acribia, 1996. p. 349-386.

7 MAC FADDIN, J.F. Biochemical tests for identification of medical bacteria. $2^{\text {nd }}$. ed. London: Williams \& Wilkins, 1980.

8 MIWA, N.; KAWAMURA, A.; MASUDA, T.; AKIYAMA, M. An outbreak of food poisoning due to egg yolk reaction-negative Staphylococcus aureus. International Journal of Food Microbiology, v. 64, p. 361-366, 2001.

9 SANTOS, E.C.; GENIGEORGIS, C.; FARVER, T.B. Prevalence of Staphylococcus aureus in raw and pasteurized milk used for commercial manufacturing of Brazilian Minas cheese. Journal Food Protection, v. 44, p. 172-176, 1991.

10 SILVA, N., JUNQUEIRA, V.C.A., SILVEIRA, N.F.A. Manual de métodos de análise microbiológica de alimentos. São Paulo: Varela, 1997.

11 SILVA, W.P.; DESTRO, M.T.; LANDGRAF, M.; FRANCO, B.D.G.M. Biochemical characteristics of typical and atypical Staphylococcus 
aureus in mastitic milk and environmental samples of Brazilian dairy farms. Brazilian Journal Microbiology, v. 31, p. 103-106, 2000.

12 ZÁRATE, V.; BELDA, C.; PÉRZ, C.; CARDELL, E. Changes in the microbial flora of tenerife goats'milk cheese during ripening. International Dairy Journal, v. 7, p. 635-641, 1997. 